\title{
Evaluation of phenolic, flavonoid contents and antioxidant activity in leaves, stem and roots of Solanum indicum Linn.
}

\author{
Mohan Brij $凶$ and Kakkar Arun
}

Received: 05.04.2019

Revised: 15.05.2019

Accepted: 04.06.2019

\begin{abstract}
The present investigation deals with the evaluation of phenolic, flavonoid contents and antioxidant activity in leaves, stem and roots of Solanum indicum. Powdered samples of leaves, stem and roots were subjected to successive extraction with solvents of increasing polarities i.e. Ethanol, Water: Ethanol (Aqua- alcoholic) (20: 80) and Water (aqueous) using soxhlet apparatus. The results showed the maximum phenolic content $(12.351 \pm 0.03 \%)$ in Aqua- alcoholic (80: 20) extract and maximum flavonoid content $(\mathbf{3 8 . 6 5 8} \pm \mathbf{0 . 0 5} \%)$ in ethanolic extract of leaves. For stem, both the maximum phenolic $(\mathbf{1 1 . 7 5 0} \pm \mathbf{0 . 0 2} \%)$ and flavonoid $(\mathbf{2 . 0 4 0} \pm \mathbf{0 . 0 3} \%)$ contents was found in Aqua- alcoholic (80: 20) extract. Similarly, the maximum phenolic $(18.651 \pm 0.03 \%)$ and flavonoid $(2.701 \pm 0.05 \%)$ contents was found in ethanolic extract of roots. The Aqua- alcoholic (80: 20) extracts for leaves and stem and ethanolic extract for roots was found to contain the maximum antioxidant activity.
\end{abstract}

Key Words: Solanum indicum, leaves, stem, roots, phenolic and flavonoid contents, antioxidant activity

\section{Introduction}

Solanum indicum L. is commonly known as Birhata or Badikateri or Indian night shade and belongs to the family Solanaceae. It is an erect under shrub of 0.30 to $1.8 \mathrm{~m}$ in height and found throughout warmer parts of India, Asia and Africa upto an elevation of $1.5 \mathrm{~m}$ (Hasan et al., 2013). The national demand of $S$. indicum is 500-1000 MT per annum (Anonymous, 2018). All plant parts viz. berries, leaves, roots, seeds and stem of this species have been utilized in traditional system of medicine and are useful in various diseases such as bronchitis, asthma, dry cough, rhinitis, dysuria, leucoderma, sexual disorders, insomnia, cardiac weakness and pruritis (Anonymous, 1986, Bhakta, 1982 , Bhattacharya, 1982 and Sharma et al., 2017). The species is among the ten medicinal plants whose roots are principally employed in preparation of Dashmoolarishta, a well-established ayurvedic drug used in the treatment of fatigue, oral sores and gynecological disorders (Yadav et al., 2009). Dashmool formulation is also utilized in the preparation of more than hundred ayurvedic drugs (Pathak et al., 2005). Phytochemicals are the natural compounds or products found in all plant

\section{Author's Address}

Natural Products Laboratory, Department of Chemistry, Govt. Science College, Jabalpur (M.P.) - 482001

E-mail.: brijmohan625@gmail.com parts and work together with nutrients and fibres to act as a defence system in plants and protect humans against diseases.These phytochemicals have specific pharmacological effects on human body such as anti-oxidants, anti-inflammatory, antiallergic, antimicrobial, hepato-protective, hypolipidemic, neuroprotective, hypotensive, antiaging, anti-diabetic, anti- cancer and cardioprotective, diuretic, CNS stimulant, analgesic, immuno-modulator etc (Prakash et al., 2012). Phenols and flavonoids are the most widely distributed phytochemicals in plants responsible for various pharmacological activities (Figure 1). The antioxidant activity of plants is of much concern in present time as antioxidants protect the human body from free radicals. Free radicals being the reactive oxygen and nitrogen species involved in the pathogenesis of several human diseases and disorders (Patel et al., 2011, Boynes, 1991). Phytochemicals such as phenolic diterpenes, flavonoids, tannins and phenolic acids of plant origin are useful sources of natural antioxidants (Lee et al., 2004). Flavonoids among polyphenols are known as the strongest antioxidant agents in plant extracts (Bernardi et al., 2008). Since the antioxidants provide immunity to the human body and protect us from a number of diseases, the search for novel natural antioxidants of plant origin 
is the major focus area of researchers these days. The scientific studies showed that antioxidant activity of plants play a major role in the protective effect of herbal medicine (Saeed et al., 2012). S. indicum is one of the commercially important medicinal plants but the evaluation of the phenolic, flavonoid contents and antioxidant activity of leaves, stem and roots of $S$. indicum is still needed which are the objectives of this study.

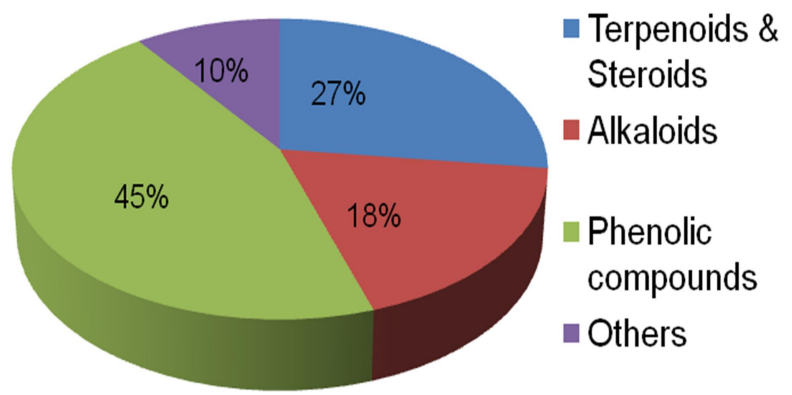

Figure 1. Major groups of plant phytochemicals (Saxena et al., 2013)

\section{Material and Methods}

Chemicals and reagents:

All chemicals, reagents and solvents used in the study were of AR grade and distilled water was utilized wherever required.

\section{Collection of plant materials:}

The plant materials (leaves, stem and roots) of $S$. indicum were collected by following the guidelines of good agricultural and collection practices (GACP) for medicinal plants (Anonymous, 2003) from the Chhindwada region of Madhya Pradesh.

\section{Processing of plant materials:}

Plant materials were washed thoroughly in running water to remove soil and other foreign particles. These were cut into small pieces and dried in shade. Shade dried plant samples were powdered using grinder mill and powdered plant materials were stored in air -tight polythene bags for further chemical analysis.

\section{Preparation of plant extracts:}

Powdered plant samples of leaves, stem and roots of selected species were subjected to successive extraction with solvents of increasing polarities i.e. Ethanol, Ethanol: Water (Aqua- alcoholic) (80: 20) and Water (aqueous) using soxhlet apparatus (Varghese et al., 2013). A total of $20 \mathrm{~g}$ of dried plant powder of concerned part was extracted in
$250 \mathrm{ml}$ of each solvent in successive manner for 12 hrs. Solvents were evaporated to dryness to yield the respective extracts which were used for estimation of antioxidant activity.

\section{Estimation of total phenols:}

Total phenols were determined by Folin Ciocalteau method (McDonald et al., 2001). $10 \mathrm{mg}$ of the extract was dissolved in a known volume of distilled water. $0.2 \mathrm{ml}$ of samples was then taken in test tube and volume made up to $3 \mathrm{ml}$ with distilled water. $0.5 \mathrm{ml}$ of Folin Ciocalteau reagent was then added. After 3 minutes, $2 \mathrm{ml}$ of $20 \% \mathrm{Na}_{2} \mathrm{CO}_{3}$ solution was added to each tube, mixed thoroughly, placed in boiling water for exactly 1 minute, cooled and absorbance was taken at $650 \mathrm{~nm}$ against blank. The phenolic content was calculated from the standard graph of catechol (figure 2).

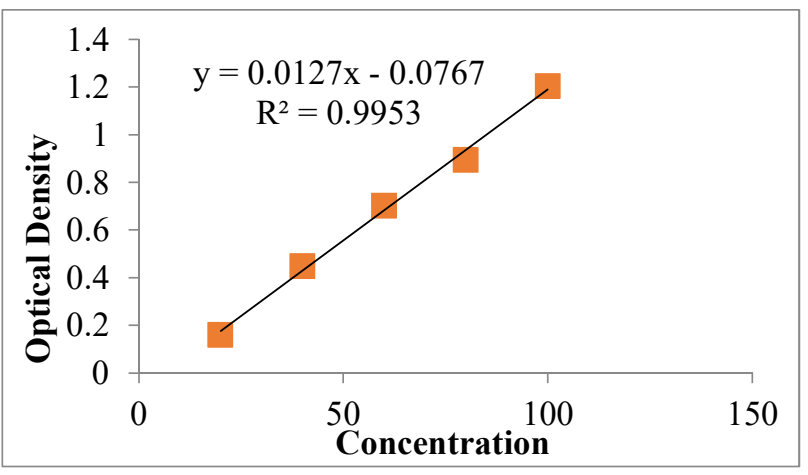

Figure 2. Standard graph of Catechol

Estimation of Flavonoids: Total flavonoids were determined by aluminum chloride colorimetric technique (Chang et al., 2002). $10 \mathrm{mg}$ of the extract was dissolved to $25 \mathrm{ml}$ with $80 \%$ ethanol. $0.5 \mathrm{ml}$ of filtrate was then mixed with $1.5 \mathrm{ml}$ of $95 \%$ ethanol, $0.1 \mathrm{ml}$ of $10 \% \mathrm{AlCl}_{3}, 0.1 \mathrm{ml}$ of potassium acetate and $2.8 \mathrm{ml}$ distilled water. The tubes were than incubated at room temperature for 30 minutes. Observation was measured at $415 \mathrm{~nm}$. The flavonoids content was calculated from the standard graph of quercetin (figure 3).

Antioxidant activity of plant extracts

DPPH radical scavenging activity assay: The free radical scavenging activity of the fractions was measured in-vitro by 1,1 - diphenyl-2picrylhydrazyl (DPPH) assay according to the method described earlier (Pandeya et al., 2016) with some modification. The stock solution was prepared by dissolving $0.006 \mathrm{~g}$ DPPH with $100 \mathrm{ml}$ 
methanol and stored at $20^{\circ} \mathrm{C}$ until required. $3 \mathrm{ml}$ aliquot of this solution was mixed with $100 \mu$ l of the sample at various concentrations $(10-50 \mu \mathrm{g} / \mathrm{ml})$. The reaction mixture was shaken well and incubated in the dark for $15 \mathrm{~min}$ at room temperature. Then the absorbance was taken at 517 $\mathrm{nm}$. The control was prepared as above without any sample. The percentage inhibition was estimated based on the percentage of DPPH radical scavenged as the following equation:

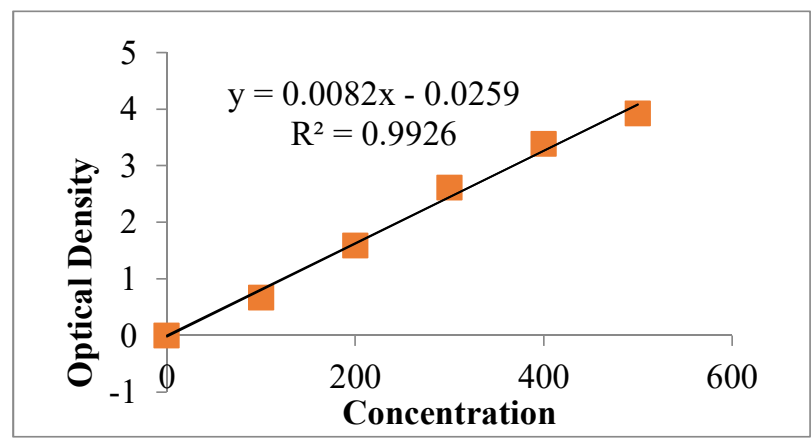

Figure 3. Standard graph of Quercetin

$\%$ Radical Scavenging Activity (RSA) $=\{($ Abs control - Abs sample) $\} /($ Abs control $) \times 100$
Where Abs control is the absorbance of the DPPH radical + methanol; Abs sample is the absorbance of DPPH radical + sample extract.

Calculation of $\mathbf{I C}_{\mathbf{5 0}}: \mathrm{IC}_{50}$ value is the concentration of the sample required to inhibit $50 \%$ of radical. $\mathrm{IC}_{50}$ values of the sample extracts were calculated.

Statistical analysis: Each experiment was carried out in triplicate and results are expressed as Mean \pm $\operatorname{SD}(n=3)$.

\section{Results and Discussion}

Total phenolic and flavonoid contents in leaf, stem and root extracts of $S$. indicum prepared in different solvents are given in Table 1. It can be seen from Table 1 that Ethanol: Water (80: 20) extract of leaves contained the maximum phenolic content $(12.351 \pm 0.03 \%)$ and ethanolic extract contained the maximum flavonoid content $(38.658 \pm 0.05 \%)$. The maximum phenolic $(11.750 \pm 0.02 \%)$ and flavonoid $(2.040 \pm 0.03 \%)$ contents was found in Ethanol: Water (80: 20) extract of stem. Similarly, the maximum phenolic $(18.651 \pm 0.03 \%)$ and flavonoid $(2.701 \pm 0.05 \%)$ contents was found in ethanolic extract of roots.

Table 1. Total phenolic, flavonoid contents in leaf, stem and root extracts of $S$. indicum

\begin{tabular}{|l|l|l|l|l|}
\hline Plant name & Parts used & Extracts & Phenols (\%) (Mean \pm SD) & Flavonoids (\%) Mean \pm SD) \\
\hline \multirow{5}{*}{ S. indicum } & Leaves & Ethanol & $12.059 \pm 0.03$ & $38.658 \pm 0.05$ \\
\cline { 3 - 4 } & Aqueous & $6.276 \pm 0.05$ & $27.643 \pm 0.02$ \\
\cline { 2 - 4 } & Stem & Aqua- alcoholic (80:20) & $12.351 \pm 0.03$ & $9.5 \pm 0.04$ \\
\cline { 3 - 5 } & Ethanol & $8.122 \pm 0.04$ & $1.164 \pm 0.09$ \\
\cline { 2 - 4 } & Aqueous & $3.885 \pm 0.01$ & $0.493 \pm 0.04$ \\
\cline { 2 - 4 } & Aqua- alcoholic (80:20) & $11.75 \pm 0.02$ & $2.040 \pm 0.03$ \\
\cline { 2 - 4 } & \multirow{4}{*}{ Roots } & Ethanol & $18.651 \pm 0.03$ & $2.701 \pm 0.05$ \\
\cline { 3 - 4 } & Aqueous & $12.702 \pm 0.02$ & $2.354 \pm 0.03$ \\
\cline { 3 - 4 } & Aqua- alcoholic (80:20) & $8.812 \pm 0.03$ & $0.555 \pm 0.06$ \\
\hline
\end{tabular}

Table 2. Antioxidant activity of leaves, roots and stem of $S$. indicum

\begin{tabular}{|c|c|c|c|}
\hline Plant name & Parts used & Extracts & $\mathrm{IC}_{50}(\mu \mathrm{g} / \mathrm{ml})$ \\
\hline \multirow{9}{*}{ S. indicum } & \multirow[t]{3}{*}{ Leaves } & Ethanol & $28.40 \pm 0.0122$ \\
\hline & & Aqueous & $23.30 \pm 0.007$ \\
\hline & & Aqua- alcoholic $(80: 20)$ & $10 \pm 0.006$ \\
\hline & \multirow[t]{3}{*}{ Stem } & Ethanol & $\mathrm{ND}^{*}$ \\
\hline & & Aqueous & $37.55 \pm 0.154$ \\
\hline & & Aqua- alcoholic $(80: 20)$ & $16.16 \pm 0.005$ \\
\hline & \multirow[t]{3}{*}{ Roots } & Ethanol & $12.89 \pm 0.004$ \\
\hline & & Aqueous & $15.88 \pm 0.013$ \\
\hline & & Aqua- alcoholic $(80: 20)$ & $36.49 \pm 0.008$ \\
\hline \multicolumn{3}{|c|}{ Ascorbic acid standard (Vitamin C) } & $42.27 \pm 0.399$ \\
\hline
\end{tabular}

*Not detected 
$\mathrm{IC}_{50}$ values $(\mu \mathrm{g} / \mathrm{ml})$ for antioxidant activity of ascorbic acid standard and leaf, stem and root extracts of $S$. indicum are presented in Table 2 and Figure 4, 5, 7, 8, 9, 10, 11, 12, 13 and 13 respectively. Fig. 5-13 shows that inhibition pattern of DPPH free radical is dose dependent. The $\mathrm{IC}_{50}$ values vary from part to part and extract to extract due to presence of different number of antioxidants.

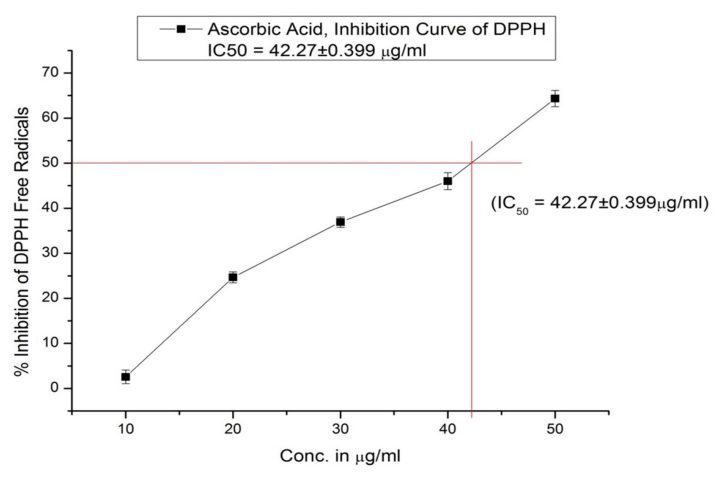

Figure 4. DPPH radical scavenging activity of Ascorbic acid

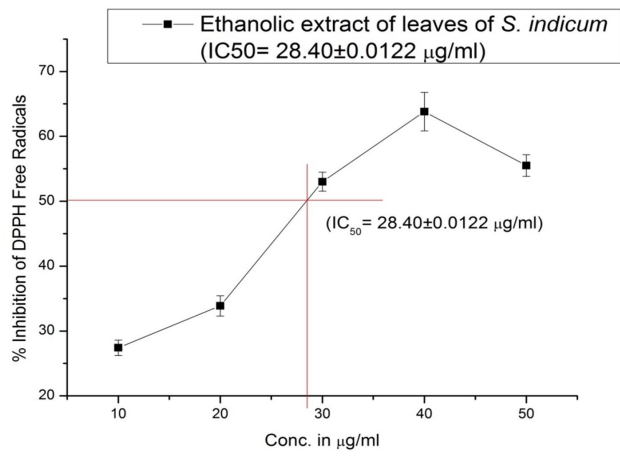

Figure 5. DPPH radical scavenging activity of ethanolic extract of $\boldsymbol{S}$. indicum leaves

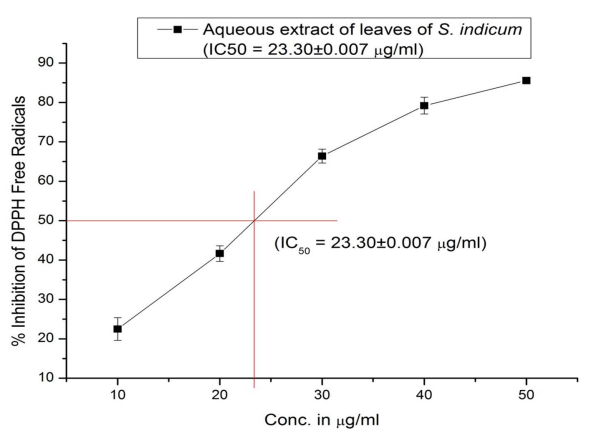

Figure 6. DPPH radical scavenging activity of aqueous extract of $S$. indicum leaves

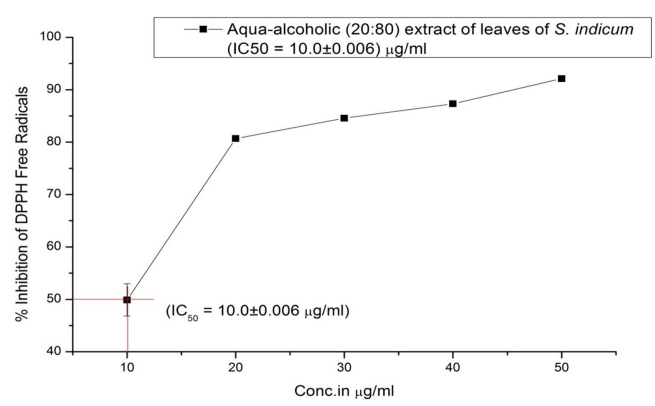

Figure 7. DPPH radical scavenging activity of Aquaalcoholic (20:80) of $S$. indicum leaves

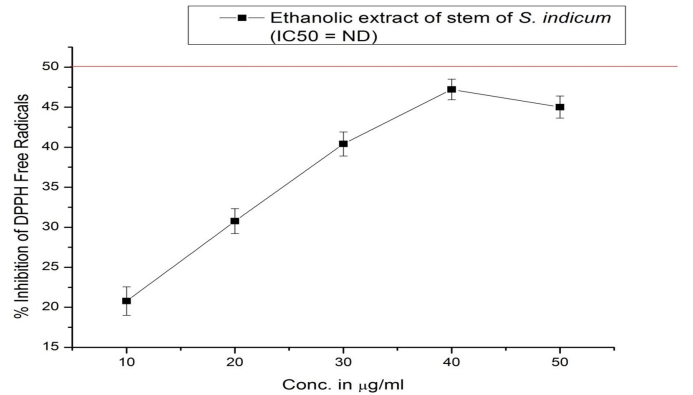

Figure 8. DPPH radical scavenging activity of ethanolic extract of $S$. indicum stem

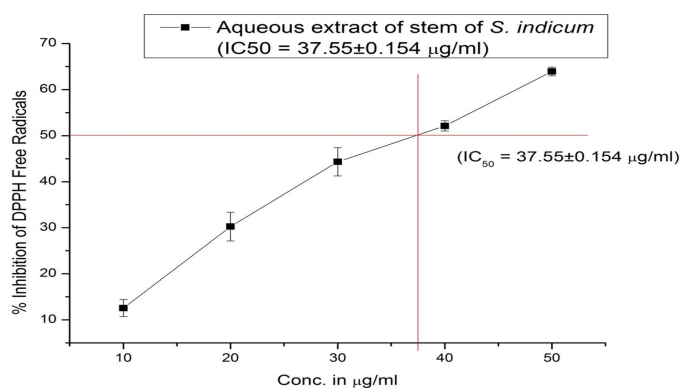

Figure 9. DPPH radical scavenging activity of aqueous extract of $S$. indicum stem

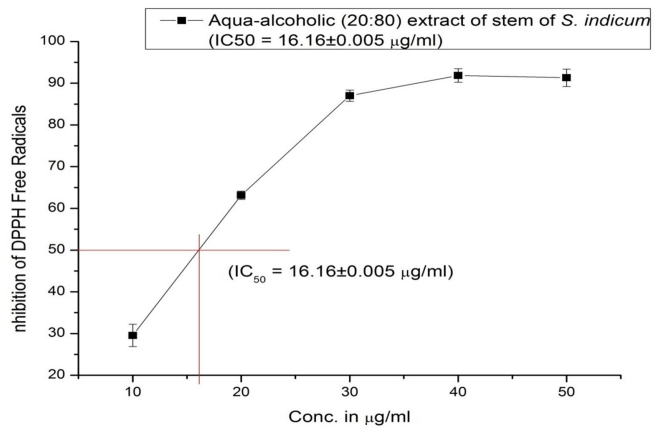

Figure 10. DPPH radical scavenging activity of Aquaalcoholic (20:80) of $S$. indicum stem 


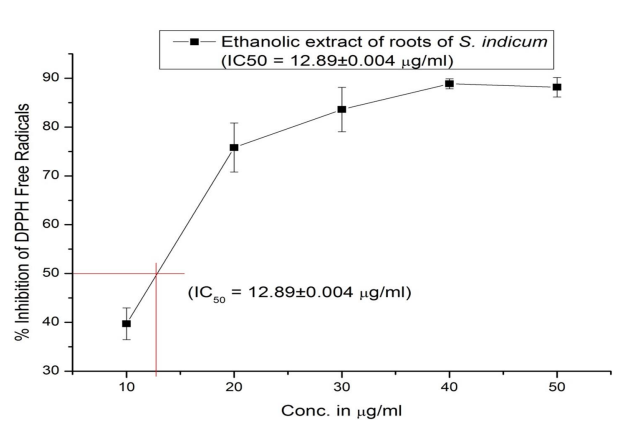

Figure 11. DPPH radical scavenging activity of ethanolic extract of $S$. indicum roots

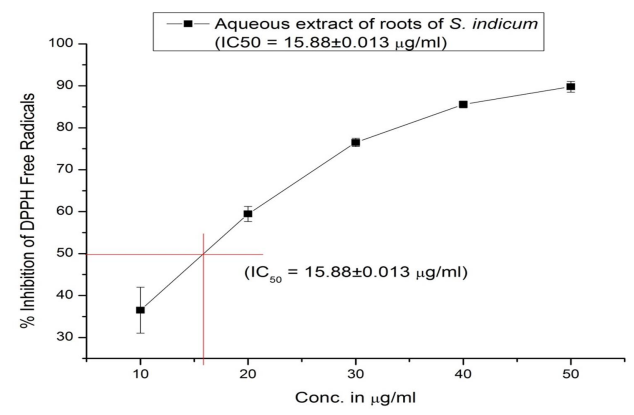

Figure 12. DPPH radical scavenging activity of aqueous extract of $S$. indicum roots

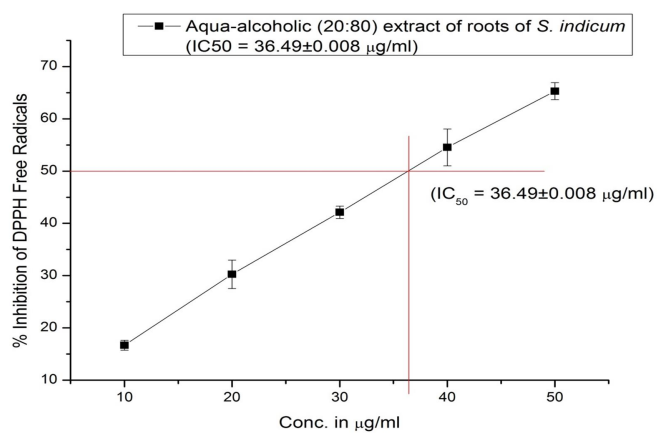

Figure 13. DPPH radical scavenging activity of Aquaalcoholic (20:80) of $S$. indicum roots

Table 2 showed that among all the three extracts of leaves and stem, Aqua- alcoholic (80:20) extract was found to have the lowest $\mathrm{IC}_{50}$ value in both the cases and hence the highest radical scavenging activity. In case of roots, the ethanolic extract was found to contain the lowest $\mathrm{IC}_{50}$ value and the highest radical scavenging activity. It can also be seen that all the extracts except the ethanolic extract of stem contained the better radical scavenging activity than ascorbic acid.
Scientific studies have proved the neutralization / scavenging effect of free radicals produced in the body with the help of antioxidants (Oboh et al., 2007). The formation of free radicals is linked with the normal metabolism of aerobic cells. The phenolics have the capability to scavenge free radicals, activate antioxidant enzymes, chelate metal catalysts, reduce $\alpha$ - tocophenol radicals and inhibit oxidases (Amic et al., 2003). Plants are the rich sources of flavonoids, isoflavones, flavones, anthocyanins, catechin and isocatechin which have been reported to bestow with tremendous antioxidant potential apart from vitamins $\mathrm{C}, \mathrm{E}$ and $\beta$ - carotene (Marin et al., 2004; Odubanjo, 2013).

Leaf, stem and root extracts of $S$. indicum showed antioxidant activity which is in agreement with the phenolic and flavonoid contents. Investigations have established the positive correlations between phenolics and antioxidant ability of some plant origin foods (Amic et al., 2003, Patel et al., 2011; Saxena et al. 2013).

\section{Conclusion}

In the present findings, it can be concluded that aqua-alcoholic extracts of leaves, stem and ethanolic extract roots of $S$. indicum exhibited significant radical scavenging ability due to the presence of phenolic and flavonoid compounds in the extracts. Further research work can also be planned for isolation and structure elucidation of responsible antioxidant components of this plant.

\section{Aknowledgement}

Author is highly grateful to the Principal of Govt. Science College, Jabalpur and Director of Tropical Forest Research Institute, Jabalpur for giving permission and providing necessary facilities to conduct the research work.

\section{References}

Amic, D., Davidovic-Amic, D., Beslo, D. and Trinajstic, N. 2003. Structure - radical scavenging activity relationship of flavonoids. Croatia Chemica Acta, 76(1): 55-61.

Anonymous. 1986. Publications and Information Directorate, CSIR. The Wealth of India - Raw Materials, New Delhi (India).

Anonymous. 2003. WHO guidelines on good agricultural and collection practices (GACP) for medicinal plants. World Health Organization, Geneva. 


\section{Mohan and Kakkar}

Anonymous. 2018. Nmpb.nic.in [homepage on the Internet]. New Delhi: National Medicinal Plants Board, Ministry of Ayush, Government of India. Available from: https://nmpb.nic.in/medicinal_list.

Bernardi, A.P.M., López-Alarcón, C., Aspée, A., Rech, S.B., Von Poser G.L., Bridi, R., Dutrafilho, C.S., and Lissi, E. 2008 Antioxidant Activity in Southern Brazil Hypericum species. Journal of the Chilean Chemical Society, 53: 1658- 1662.

Bhakta, T. 2004. Common Vegetables of the Tribals of Tripura. Agartala (India): Tripura Tribal Research Institute.

Bhattacharya, A.S. 1982. Chiranjivi Banaushadhi. $2^{\text {nd }}$ Vol, $3^{\text {rd }}$ reprint. Kolkata: Ananda Publishers.

Boynes, J.W. 1991 Role of oxidative stress in development of complication in diabetes. Diabetes, 40: 405-411.

Chang, C., Yang, M., Wen, H. and Chern, J. 2002. Estimation of total flavonoid content in propolis by two complementary colorimetric methods. Journal of Food and Drug Analysis, 10:178-182.

Hasan, R.U., Prabhat, P., Shafaat, K. and Khan, R. 2013. Phytochemical investigation and evaluation of antioxidant activity of fruit of Solanum indicum L. International Journal of Pharmaceutical Sciences and Research, 5(3):237-42

Lee, J.C., Lee, K.Y., Kim, J., Na, C.S., Jung, N.C., Chung, G.H. and Jang, Y.S. 2004. Extract from Rhusverniciflua stokes is capable of inhibiting the growth of human lymphoma cells. Food and Chemical Toxicology, 42 (9): 1383-1388.

Marin, A., Ferreres, F., Tomas-Barberan, F.A. and Gil, M.J. 2004. Characterization and quantitation of antioxidant constituents of sweet pepper (Capsicum annuum L). Journal of Agricultural and Food Chemistry, 52:38613869 .

McDonald, S., Prenzler, P.D., Autolovich, M. and Robards, K. (2001) Phenolic content and antioxidant activity of olive extracts. Food Chemistry, 73:73-84.

Oboh, G., Puntel, R.L. and Rocha, J.B.T. 2007. Hot pepper (Capsicum annuum, Tepin \& Capsicum chinese, Habanero) prevents $\mathrm{Fe}^{2+}$ induced lipid peroxidation in Brain-In vitro. Food Chemistry, 102(1):178-185.
Odubanjo, V.O., Oboh, G. and Ibukun, E.O. 2013. Antioxidant and anticholinesterase activities of aqueous extract of Uraria picta (Jacq.) DC. African Journal of Pharmacy and Pharmacology, 7(41): 2768-2773.

Pandeya, K.B., Tripathi, I.P., Mishra. M.K. and Jaiswal, N. 2016. Antiradical and Antioxidant properties of some oxovanadium (IV) complexes of 1-amino acids. Journal of Biological Sciences and Medicine, 2(4): 38-47.

Patel, B.D., Kamariya, Y.H. and Patel, M.B. 2011. Antioxidant potential of aqueous extract of entire plant of Uraria picta Desv. International Journal of Pharmaceutical Research, 3 (4): 92-96.

Pathak, J.M., Krishnamurthy, R., Chandorkar, M.S., Gulkari, V .D. and Rajendra, G. 2005. Identification of high yielding genotypes of Dashmool Shalparni (Desmodium gangeticum) drug plant and its cultivation under high density planting. Indian Journal of Horticulture, 62(4): 378-84

Prakash, D., Gupta, C. and Sharma, G. 2012. Importance of Phytochemicals in Nutraceuticals. Journal of Chinese Medicine Research and Developmen, 1(3): 70-78.

Saeed, N., Khan, M.R. and Shabbir, M. 2012. Antioxidant activity, total phenolic and total flavonoid contents of whole plant extracts Torilis leptophylla L. BMC Complementary and Alternative Medicine, 12: 221.

Saxena, M., Jyoti, S., Nema, R., Dharmendra, S. and Abhishek, G. 2013. Phytochemistry of Medicinal Plants. Journal of Pharmacognosy and Phytochemistry, 1 (6): 168-182.

Sharma, V., Hem, K., Seth, A. And Maurya, S.K. 2017. Solanum indicum Linn.: An ethnopharmacological, phytochemical and pharmacological review. Current Research Journal of Pharmaceutical and Allied Sciences, $1(2): 1-9$

Varghese, S., Narmadha, R., Gomathi, D., Kalaiselvi, M. and Devaki, K. 2013 Phytochemical screening and HPTLC finger printing analysis of Citrullus lanatus (Thunb.) seed. Journal of Acute Disease, 2(2): 122-126.

Yadav, A.K., Yadav, D., Shanker, K., Verma, R.K., Saxena, A.K. and Gupta, M.M. 2009. Flavone Glycoside Based Validated RP-LC Method for Quality Evaluation of Prishniparni (Uraria picta). Chromatographia, 69 (7-8): 653-8. 